\title{
Investigating Influential Factors on Improving Poverty Conditions in Latin America
}

\author{
Keisuke Mitsumoto, Koichi Yamaura* \\ Department of International, Environmental and Agricultural Science, Tokyo University of Agriculture and Technology, \\ Tokyo, Japan \\ Email: ^kyamaura@cc.tuat.ac.jp
}

How to cite this paper: Mitsumoto, K. and Yamaura, K. (2018) Investigating Influential Factors on Improving Poverty Conditions in Latin America. Journal of Human Resource and Sustainability Studies, 6, 171-184.

https://doi.org/10.4236/jhrss.2018.62035

Received: March 29, 2018

Accepted: June 1, 2018

Published: June 4, 2018

Copyright $\odot 2018$ by authors and Scientific Research Publishing Inc. This work is licensed under the Creative Commons Attribution International License (CC BY 4.0).

http://creativecommons.org/licenses/by/4.0/

\begin{abstract}
The objective of this study is to determine the spillover effects of various international supports for poverty in Paraguay. A vector autoregressive model is used to investigate a dynamic linkage among five components: prevalence of undernourishment, food intake, gross domestic products (GDP) per capita, primary school completion rate, and unemployment rate. We found that the primary school completion rate has the largest spillover effects for reducing poverty except GDP per capita. Supporting international agencies such as the Inter-American Development Bank can keep or invest more money in early education sectors, and $\mathrm{Pa}$ raguay can obtain not only direct supports but also larger indirect effects.
\end{abstract}

\section{Keywords}

VAR, Paraguay, Poverty

\section{Introduction}

Poverty is a crucial global issue that must be solved; thus, one of the Millennium Development Goals (MDGs) set by the United Nations (UN) in 2000 is to "eradicate extreme poverty and hunger" (Table 1). The UN adopted the Sustainable Development Goals (SDGs) in 2015 to replace the MDGs. The SDGs expand the MDGs, and they include seventeen development goals including "no poverty"; this goal focuses on ending poverty in all forms and dimensions by 2030 (Table 1). However, twenty percent of the population in under-developed countries have still lived on less than US $\$ 1.90$ a day, today ${ }^{1}$. People in these countries have ${ }^{1}$ The World Bank set the new global poverty line at US $\$ 1.90$ based on the 2011 purchasing power parity (PPP) (World Bank:

https://datahelpdesk.worldbank.org/knowledgebase/articles/746163-what-is-the-1-90-poverty-line-a nd-based-on-this). A $10.7 \%$ of world total is under the US $\$ 1.90$ poverty line, while the average US household spends US\$ 157.02 per day in 2016 (Bureau of Labor Statistics: https://www.bls.gov/news.release/cesan.nr0.htm). 
Table 1. List of millennium development goals and sustainable development goals.

\begin{tabular}{lccc}
\hline & MDGs & & SDGs \\
\hline 1 & Eradicate extreme poverty and hunger & 1 & No poverty \\
3 & Achieve universal primary education & 2 & Zero hunger \\
4 & Promote gender equality and empower women & 3 & Good health and well-being \\
5 & 4 & Quality education \\
6 & Combat HIV/AIDS, malaria and other diseases & 6 & Clean water and sanitation \\
7 & Ensure environmental sustainability & 7 & Affordable and clean energy \\
8 & Global partnership for development & 8 & Decent work and economic growth \\
& 9 & Industry innovation and infrastructure \\
& 10 & Reduced inequalities \\
& 11 & Sustainable cities and communities \\
& 12 & Responsible consumption and protection
\end{tabular}

Source: The United Nations: http://www.un.org/en/index.html.

still lacked accesses to adequate food, clean drinking water, and sanitation, even though global extreme poverty rates have decreased more than half since 1990. For instance, Paraguay decreased its poverty rate from twelve percent in 1995 to less than three percent in 2015 (Figure 1). In addition, gender is key to poverty rates; women in these under-developed countries are more likely to live in poverty conditions than men because of their uneven access to work, education, and property [1].

People living in poverty not only lack money (i.e., due to lower incomes) but also face other challenges. The United Nations Development Programme (UNDP) stated that poverty issues including women's illiterate and higher child mortality rate should be solved simultaneously. Additionally, poverty can involve not only a lack of necessities required for material well-being but also the denial of opportunities to live a tolerable life [2]. Based on the poverty dimensionality [2], a multidimensional social phenomenon, whose causes vary by gender, age, and other socio-economic contexts, was defined by [3]. Poverty has various causes, such as shortage of food or farmland, lack of access to clean water, unemployment, and/or lower education levels [1].

[4] conducted a study on relationships between income distribution and socioeconomic variables. He explored Malaysian poverty and income distribution using an enumeration survey focused on socioeconomic variables such as race, 


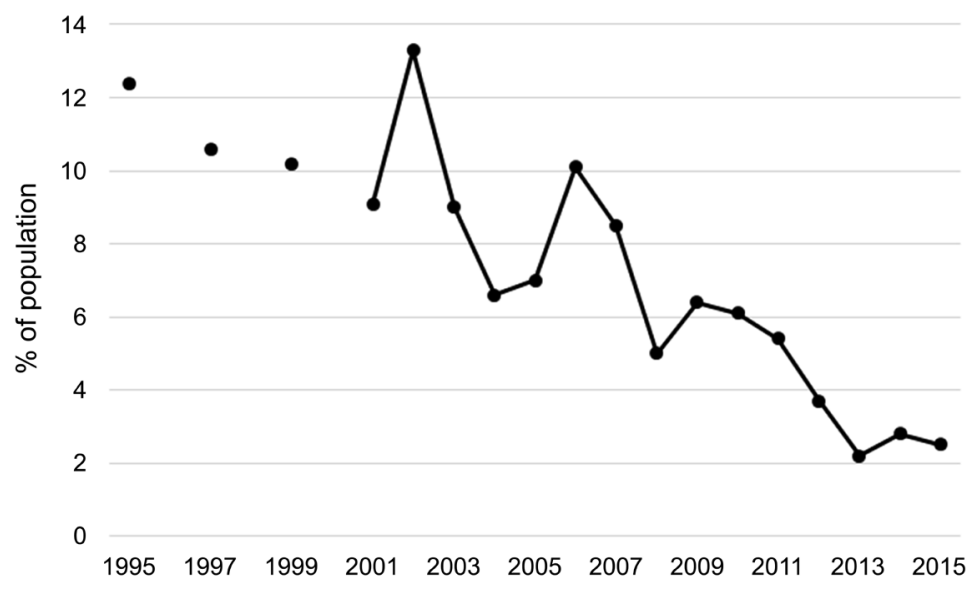

Figure 1. Paraguayan poverty headcount ratio at $\$ 1.90$ a day (2011 PPP). Source: World Bank Open Data (https://data.worldbank.org/).

location, employment status, occupation, and education. [4] found that income gaps came from the difference of race, and suggested that the government implements appropriate new policies to combat the poverty. In another study focused on the scale of poverty, [5] attempted to present a new multidimensional poverty index (MPI) for scaling the poverty based on a household survey dataset from 104 under-developed countries. They used three dimensions: education, health, and standard of living for accessing poverty, and each dimension has multi-indicators. For instance, a year of schooling and child school attendance are in the educational dimension; mortality and nutrition are in the health dimension; and electricity, sanitation, water, floor (i.e., whether the household has a dirt, sand, or dung floor), cooking fuel, and assets are indicators of the standard of living dimension [5].

For estimating the poverty issues, [6] used a vector autoregressive (VAR) approach for examining the implication of unemployment and inflation on the poverty in Nigeria. Their VAR analysis includes poverty level, unemployment rate, and inflation rate. They found that an unemployment caused poverty in Nigeria, and recommended the government would expand educational programs to acquire the practical skills [6]. Another study on the poverty is [7]. They examined the nexus between the financial sector development and poverty reductions in Nigeria, and found that indirect economic effects of economic growth had the strongest influence on the poverty reduction in the short term, while it would widen the income inequality in the long term [7].

\section{Poverty in Latin America}

In this century, many under-developed countries in Southern Asia, North and Sub-Saharan Africa, and Central and South America have still suffered the poverty. Focusing on Latin America, various researches on poverty were conducted for reducing this social issue. The World Bank summarized the poverty in South America [8] [9]. There were thirty-five million Brazilians have suffered from ex- 
treme poverty. This constituted 22.6 percent of their population although Brazil made great economic advances in improving their social indicators (e.g., the infant mortality rate and the rate of non-enrollment in the primary school). In addition, Brazil has had intense income inequality and high unemployment rate. The higher income inequality and the unemployment rate have led to the higher level of crime [10] [11]. As a result, Brazil has largely suffered high crime rates. Argentina is another high-income country in the Latin America, which annual per capita income is over US $\$ 8000$ [8]. Despite its wealth, Argentina has also been suffered from high level of the poverty though poverty rates fell forty percent in 1990 to twenty-two percent in 1994. However, income distribution has worsened since more skilled and educated people gained larger income in Argentina. Not only Argentina and Brazil, but the other Latin American countries have faced these issues. Therefore, South America is one of the highest poverty regions in the world.

For improving poverty conditions, the Inter-American Development Bank (IDB), the UN, the Japan International Cooperation Agency (JICA), and other organizations have largely supported Central and South America. For supporting these countries, these agencies often set the target sector(s) that they mainly support in the year. For instance, infrastructure and environment sectors were main target sectors of the IDB supports in 2016. Especially, the IDB focuses on a transport sector and a water and sanitation sector, and the total costs of projects in Brazil were 135 billion US dollars between 1961 and 2016. This is the largest supports in Latin America, while the IDB has supported 64 billion US dollars in Argentina between 1961 and 2016, which is the thirdlargestsupports ${ }^{2}$.

Similar to the other South American countries, Paraguay has historically suffered from poverty and plagued by corruption and political instability. According to the [12], approximately forty percent of Paraguayan population is poor, and twenty percent are extremely poor. The incidence of poverty illustrates variations across regions: Asuncion, the capital of Paraguay, is lowest and 21 percent, urban region outside central is $27 \%$, urban central is $35.3 \%$ and rural household is $48.8 \%$ [12]. Paraguayan poverty is intense that over half of the poor and more than two-thirds of the extremely poor are located in the rural area. This occurred under the dictatorship of General Alfredo Stroessner from 1954 to 1969 [12]. During this term, agricultural growth was achieved through foreigner's agricultural migration policies by 1969 . The Paraguayan government introduced a foreign currency and market-open policies, establishing industrial growth in the 1970s. These policies also led to the uneven distribution of agricultural land that $1.1 \%$ of the population owned approximately eighty percent of agricultural land (Table 2). In other words, over eighty percent of small farmers who owned land up to twenty hectors are only 6.2 percent of agricultural land in Paraguay, indicating that the smaller agricultural land led to the lower income for the farmer. Due to this historical background, the poverty has been widespread with increasing poverty gap in Paraguay [12] [13].

${ }^{2}$ Mexico received the second largest supports by the IDB. 
Table 2. Overall land distribution in Paraguay in 1991.

\begin{tabular}{ccc}
\hline Size (ha) & Farmer (\% of total) & Land (\% of total) \\
\hline $0-5$ & 38.4 & 1.0 \\
$5-10$ & 22.3 & 1.8 \\
$10-20$ & 22.1 & 3.4 \\
$20-50$ & 19.5 & 3.6 \\
$50-100$ & 2.5 & 2.1 \\
$100-1000$ & 3.1 & 8.7 \\
$1000<$ & 1.1 & 79.5 \\
Total & 100 & 100 \\
\hline
\end{tabular}

Source: Paraguay Agricultural Census, 1999:

http://www.fao.org/fileadmin/templates/ess/documents/world_census_of_agriculture/main_results_by_cou ntry/Paraguay_1991.pdf.

Organizations such as the International Bank for Reconstruction and Development (IBRD), the International Development Association, the IDB, the JICA and the UN have supported Paraguay to reduce the poverty. The largest supporter, the IDB, has given priorities to interventions in following six sectors: transportation and connectivity, water and sanitation, energy, productive development, finance, and public management. Total loans from the IDB were 1.57 billion US dollars in 2013, and total amounts of the IBRD loans and the IDA credits were 430 million US dollars in 2015 . Due to these supports, the poverty rate has rapidly decreased in Paraguay after 2006 (Figure 1). However, there are still many Paraguayan under the poverty, and it is important to improve the poverty conditions [12]. For reducing poverty, there have been various supports by international agencies. If there are spillover effects from one support in a certain field, it will lead to effective poverty reduction. Clarifying spillover effects are important both for Paraguay and supporting agencies. When we know indirect spillover effects of direct supports, international agencies such as the IDB or the UN can invest money more effectively. However, there is no study of clarifying indirect effects in Paraguay. Therefore, the objective of this study is to determine spillover effects of various international agencies' supports for poverty in Paraguay.

\section{Methodology}

Following [2] and [3], this study uses multi-dimensional aspects of Paraguayan poverty analysis for clarifying spillover effects of international supports for reducing poverty in Paraguay. We select four multi-dimensional aspects: food, economy, education, and work. First, this study divides a food dimension into two: food quality and food quantity. The prevalence of undernourishment is chosen as the food quality dimensional aspect, while the food intake is used as the food quality aspect. The prevalence of undernourishment measures the share of the population who has an insufficient caloric intake to meet the minimum 
energy requirements defined as a given population ${ }^{3}$. The food intake that indicates a national average food intake. Next, we choose dimensional aspects of economy, education, and work are the gross domestic product (GDP) per capita, the primary school completion rate, and the unemployment rate, respectively. The GDP per capita captures Paraguayan average income status, and the unemployment rate illustrates labor and economy. The primary school completion rate is the percentage of students completing the last year of a primary school. This captures the population of early education in Paraguay. Unlike the Malaysian case [4], this study does not include race because of the lack of Paraguayan data. Therefore, there are five indicators: prevalence of undernourishment, food intake, GDP per capita, primary school completion rate, and unemployment rate for revealing spillover effects of international agencies' supports in Paraguay. This study uses the VAR model to disclose the relationship among five indicators for reducing poverty in Paraguay since the VAR model can detect relationships among variables, can forecast future influences among each other, and can be relatively easy to estimate with small dataset [6] [7] [14] [15].

The Equations (1)-(5) show the five-equation system of reducing Paraguayan poverty factors including prevalence of undernourishment (PREUN), food intake (FOOD), GDP per capita (GDP), primary school completion rate (PRICR), and unemployment rate (UNEMP) as:

$$
\begin{aligned}
& \ln \text { PREUN }_{t}=k_{1}+a_{1} t+\sum_{i=1}^{n} b_{1 i} \ln \text { PREUN }_{t-1}+\sum_{i=1}^{n} c_{1 i} \ln \text { FOODS }_{t-1} \\
& +\sum_{i=1}^{n} d_{1 i} \ln \mathrm{GDP}_{t-1}+\sum_{i=1}^{n} f_{1 i} \ln \mathrm{PRICR}_{t-1} \\
& +\sum_{i=1}^{n} g_{1 i} \ln \mathrm{UNEMP}_{t-1}+e_{1 t} \text {, } \\
& \ln \mathrm{FOODS}_{t}=k_{2}+a_{2} t+\sum_{i=1}^{n} b_{2 i} \ln \text { PREUN }_{t-1}+\sum_{i=1}^{n} c_{2 i} \ln \text { FOODS }_{t-1} \\
& +\sum_{i=1}^{n} d_{2 i} \ln _{\mathrm{GDP}_{t-1}}+\sum_{i=1}^{n} f_{2 i} \ln \mathrm{PRICR}_{t-1} \\
& +\sum_{i=1}^{n} g_{2 i} \ln \mathrm{UNEMP}_{t-1}+e_{2 t} \text {, } \\
& \ln \mathrm{GDP}_{t}=k_{3}+a_{3} t+\sum_{i=1}^{n} b_{3 i} \ln \mathrm{PREUN}_{t-1}+\sum_{i=1}^{n} c_{3 i} \ln _{\mathrm{FOODS}_{t-1}} \\
& +\sum_{i=1}^{n} d_{3 i} \ln \mathrm{GDP}_{t-1}+\sum_{i=1}^{n} f_{3 i} \ln \mathrm{PRICR}_{t-1} \\
& +\sum_{i=1}^{n} g_{3 i} \ln \mathrm{UNEMP}_{t-1}+e_{3 t}, \\
& \ln \text { PRICR }_{t}=k_{4}+a_{4} t+\sum_{i=1}^{n} b_{4 i} \ln \text { PREUN }_{t-1}+\sum_{i=1}^{n} c_{4 i} \ln \text { FOODS }_{t-1} \\
& +\sum_{i=1}^{n} d_{4 i} \ln \mathrm{GDP}_{t-1}+\sum_{i=1}^{n} f_{4 i} \ln \mathrm{PRICR}_{t-1} \\
& +\sum_{i=1}^{n} g_{4 i} \ln \mathrm{UNEMP}_{t-1}+e_{4 t} \text {, } \\
& \ln \mathrm{UNEMP}_{t}=k_{5}+a_{5} t+\sum_{i=1}^{n} b_{5 i} \ln \mathrm{PREUN}_{t-1}+\sum_{i=1}^{n} c_{5 i} \ln \mathrm{FOODS}_{t-1} \\
& +\sum_{i=1}^{n} d_{5 i} \ln \mathrm{GDP}_{t-1}+\sum_{i=1}^{n} f_{5 i} \ln \mathrm{PRICR}_{t-1} \\
& +\sum_{i=1}^{n} g_{5 i} \ln \mathrm{UNEMP}_{t-1}+e_{5 t} \text {, }
\end{aligned}
$$

where $t$ is time in years, $n$ is number of lags, $k, a, b, c, d, f$ and $g$ are estimated parameters, and $e_{10} e_{2 b} e_{30} e_{4 t}$ and $e_{5 t}$ are the error terms for each equation.

${ }^{3}$ World Bank: http://www.fao.org/sustainable-development-goals/indicators/211/en/. 
For determining spillover effects of Paraguayan poverty supports, we use food, economy, education and work data. Because of data limitation before 1995, yearly data from 1995 to 2012 are used in this analysis. The yearly prevalence of undernourishment (percentage of population), GDP per capita (2016 US dollars), primary school completion rate (percentage of relevant age group), and unemployment rate (percentage of total labor force) are obtained from the World Bank Open Data ${ }^{4}$. The yearly food intake data (kcal/capita/day) is obtained from the Food and Agriculture Organization of United Nations $s^{5}$. The summary statistics of Paraguayan dataset are in Table 3. The average prevalence of undernourishment during eighteen years sample period was $12.73 \%$. This is slightly higher than the 2012 global total, $11 \%^{6}$. The mean of primary completion rate was $91.33 \%$ which was close to the 2012 global total, $91.4 \%{ }^{7}$. The average Paraguayan unemployment between 1995 and 2012 is similar to that of global total, $6.19 \%^{8}$. The R program with the vars package was used for this estimation.

\section{Results}

We use the VAR model for the estimation of the spillover effects in the Paraguayan development supports. To interpret the economic implications, first, we estimate the VAR model with causality tests (Table 4 ). Then, we calculate impulse responses (Figures 2-6) and forecast error decomposition (Table 5) for analyzing the spillover effects of Paraguayan supports.

First, Granger causality tests were conducted to identify if any variables could be used in predicting other variables [15]. Table 4 shows the estimated VAR model results including Granger causality tests. The causality results indicate that the variables do not cause any of the other variables besides themselves. Therefore, all variables have a granger cause, indicating that prevalence of undernourishment, food intake, GDP per capita, primary school completion rate, and unemployment rate can be explained by the other variables.

Second, the impulse response function identifies the responses over time in all variables to a one-standard-deviation increase in one of the variables [16]. The system is triangularized with the variables ordered as prevalence of undernourishment, food intake, GDP per capita, primary school completion rate, and unemployment rate. The ordering for variables is based on prior knowledge and of the variable exogeneity and comparisons of alternative ordering [16]. Figures 2-6 illustrate the impact of a shock in one variable on the other variables. Figure 2 indicates that a positive shock in prevalence of undernourishment results in some small positive response by GDP per capita and unemployment rate, while

${ }^{4}$ World Bank, https://data.worldbank.org/.

${ }^{5} \mathrm{FAO}$, http://www.fao.org/home/en/.

${ }^{6}$ World Bank, Prevalence of undernourishment (\% of population):

https://data.worldbank.org/indicator/sn.itk.defc.zs.

${ }^{7}$ World Bank, Primary completion rate, total (\% of relevant age group):

https://data.worldbank.org/indicator/SE.PRM.CMPT.ZS.

${ }^{8}$ World Bank, Unemployment, total (\% of total labor force):

https://data.worldbank.org/indicator/SL.UEM.TOTL.ZS. 
Table 3. Variable definitions and summary statistics, 1995-2012.

\begin{tabular}{cccccc}
\hline Variables & Definition & Mean & Std. Dev. & Minimum & Maximum \\
\hline PREUN & $\begin{array}{c}\text { Prevalence of undernourishment } \\
\text { (\% of population) }\end{array}$ & 12.73 & 1.68 & 10.50 & 16.50 \\
FOODS & Food supply (kcal/capita/day) & 2603.00 & 51.96 & 2528.00 & 2732.00 \\
GDP & GDP per capita (2016 US\$) & 1868.33 & 709.94 & 1050.00 & 3430.00 \\
PRICR & $\begin{array}{c}\text { Primary completion rate, total } \\
\text { (\% of relevant age group) }\end{array}$ & 91.33 & 4.55 & 78.42 & 96.44 \\
& $\begin{array}{c}\text { Unemployment rate, total } \\
\text { (\% of total labor force) }\end{array}$ & 6.18 & 1.64 & 3.40 & 10.70 \\
\hline
\end{tabular}

Source: Prevalence of undernourishment, GDP per capita, primary school completion rate and unemployment rate were converted from World Bank Open Data (https://data.worldbank.org/). Food intake was obtained from statistics at Food and Agriculture Organization of United Nations (http://www.fao.org/faostat/en/).

Table 4. Estimated VAR coefficients, test statistics, and matrices of residuals for PREUN, FOODS, GDP, PRICR and UNEMP in Paraguay.

\begin{tabular}{|c|c|c|c|c|c|c|c|c|c|}
\hline & PREUN & & FOODS & GDP & & PRICR & \multicolumn{3}{|c|}{ UNEMP } \\
\hline Adjust R-squared & 0.9890 & & 0.5159 & 0.9645 & & 0.8614 & & 0.5572 & \\
\hline \multicolumn{10}{|c|}{ Granger causality } \\
\hline for PREUN [a] & 9.1414 & $* * *$ & & & & & & & \\
\hline for FOODS [b] & & & 7.6263 & $* * *$ & & & & & \\
\hline for GDP [c] & & & & 3.4814 & $* *$ & & & & \\
\hline for PRICR [d] & & & & & & 2.3903 & * & & \\
\hline for UNEMP [e] & & & & & & & & 6.6239 & $* * *$ \\
\hline $\begin{array}{l}\text { Independent } \\
\text { Variables }\end{array}$ & \multicolumn{9}{|c|}{ Regression Coefficients } \\
\hline Intercept & 11.5704 & $* * *$ & 4.9603 & 11.2980 & & 5.6767 & * & 9.2032 & \\
\hline Time Trend & -0.0139 & $* *$ & 0.0042 & 0.0388 & & -0.0125 & $* *$ & 0.0428 & \\
\hline PREUN t-1 & 0.2820 & & 0.2466 & 0.0874 & & -0.4954 & $* *$ & 2.9990 & \\
\hline FOODS $\mathrm{t}-1$ & -1.3923 & $* * *$ & 0.2581 & -0.6603 & & -0.1872 & & -3.3708 & \\
\hline GDP $t-1$ & 0.1170 & * & -0.0594 & 0.6258 & $* *$ & 0.1248 & * & -1.0146 & \\
\hline PRICR $t-1$ & 0.1174 & & 0.1288 & -0.7065 & & 0.1302 & & 4.0016 & * \\
\hline UNEMP $\mathrm{t}-1$ & -0.0421 & & 0.0360 & -0.3846 & $* *$ & 0.1034 & ** & 0.2927 & \\
\hline & \multicolumn{9}{|c|}{ Covariance Matrix of Residuals } \\
\hline PREUN & 0.00016 & & -0.00014 & 0.00029 & & 0.00009 & & 0.00001 & \\
\hline FOODS & -0.00014 & & 0.00021 & -0.00017 & & -0.00008 & & -0.00024 & \\
\hline GDP & 0.00029 & & -0.00017 & 0.00417 & & 0.00017 & & -0.00593 & \\
\hline PRICR & 0.00009 & & -0.00008 & 0.00017 & & 0.00022 & & 0.00104 & \\
\hline UNEMP & 0.00001 & & -0.00024 & -0.00593 & & 0.00104 & & 0.02402 & \\
\hline
\end{tabular}


Continued

$\begin{array}{cccccc}\text { PREUN } & 1.00000 & -0.76610 & 0.36310 & 0.48470 & 0.00598 \\ \text { FOODS } & -0.76606 & 1.00000 & -0.18500 & -0.37810 & -0.10836 \\ \text { GDP } & 0.36312 & -0.18500 & 1.00000 & 0.17560 & -0.59260 \\ \text { PRICR } & 0.48466 & -0.37810 & 0.17560 & 1.00000 & 0.45546 \\ \text { UNEMP } & 0.00598 & -0.10840 & -0.59260 & 0.45550 & 1.00000\end{array}$

$* * *, * *$, and ${ }^{*}$ indicate significance at $1 \%, 5 \%$, and $10 \%$ level, respectively. [a] F-value for testing $\mathrm{H}_{0}$ : PREUN do not Granger-cause FOODS GDP PRICR UNEMP. [b]F-value for testing $\mathrm{H}_{0}$ : FOODS do not Granger-cause PREUN GDP PRICR UNEMP. [c] F-value for testing $\mathrm{H}_{0}$ : GDP do not Granger-cause PREUN FOODS PRICR UNEMP. [d] F-value for testing $\mathrm{H}_{0}$ : PRICR do not Granger-cause PREUN FOODS GDP UNEMP. [e] F-value for testing $\mathrm{H}_{0}$ : UNEMP do not Granger-cause PREUN FOODS GDP PRICR.

Table 5. The proportions of k-years-ahead forecast error attributed to innovations in respective series.

\begin{tabular}{|c|c|c|c|c|c|c|}
\hline & \multirow{2}{*}{$\begin{array}{c}\text { Years } \\
\text { ahead }\end{array}$} & \multicolumn{5}{|c|}{ Proportion of Error Explained by: } \\
\hline & & PREUN & FOODS & GDP & PRICR & UNEMP \\
\hline \multirow[t]{5}{*}{ PREUN } & 1 & 1.00000 & 0.00000 & 0.00000 & 0.00000 & 0.00000 \\
\hline & 2 & 0.72239 & 0.12559 & 0.13315 & 0.00381 & 0.01506 \\
\hline & 3 & 0.37389 & 0.06359 & 0.40556 & 0.10104 & 0.05591 \\
\hline & 4 & 0.22866 & 0.07324 & 0.41176 & 0.19930 & 0.08705 \\
\hline & 5 & 0.21064 & 0.10141 & 0.35787 & 0.23595 & 0.09413 \\
\hline \multirow[t]{5}{*}{ FOODS } & 1 & 0.58685 & 0.41315 & 0.00000 & 0.00000 & 0.00000 \\
\hline & 2 & 0.42215 & 0.29997 & 0.17096 & 0.07191 & 0.03502 \\
\hline & 3 & 0.36145 & 0.23351 & 0.20413 & 0.14652 & 0.05441 \\
\hline & 4 & 0.35712 & 0.23538 & 0.17896 & 0.16887 & 0.05966 \\
\hline & 5 & 0.35277 & 0.23773 & 0.17404 & 0.17446 & 0.06100 \\
\hline \multirow[t]{5}{*}{ GDP } & 1 & 0.13186 & 0.02103 & 0.84711 & 0.00000 & 0.00000 \\
\hline & 2 & 0.06723 & 0.01392 & 0.70557 & 0.12397 & 0.08931 \\
\hline & 3 & 0.04282 & 0.03018 & 0.61720 & 0.20895 & 0.10084 \\
\hline & 4 & 0.06262 & 0.06193 & 0.50879 & 0.25455 & 0.11210 \\
\hline & 5 & 0.07543 & 0.07959 & 0.45382 & 0.27640 & 0.11477 \\
\hline \multirow[t]{5}{*}{ PRICR } & 1 & 0.23490 & 0.00011 & 0.00000 & 0.76499 & 0.00000 \\
\hline & 2 & 0.12249 & 0.02426 & 0.01546 & 0.63782 & 0.19997 \\
\hline & 3 & 0.11310 & 0.02397 & 0.05622 & 0.62191 & 0.18480 \\
\hline & 4 & 0.09355 & 0.02977 & 0.11594 & 0.57001 & 0.19073 \\
\hline & 5 & 0.09498 & 0.03852 & 0.15669 & 0.53377 & 0.17603 \\
\hline \multirow[t]{5}{*}{ UNEMP } & 1 & 0.00004 & 0.02607 & 0.38536 & 0.26663 & 0.32190 \\
\hline & 2 & 0.13540 & 0.06366 & 0.36496 & 0.25649 & 0.17948 \\
\hline & 3 & 0.16521 & 0.11596 & 0.28702 & 0.26609 & 0.16572 \\
\hline & 4 & 0.16583 & 0.12163 & 0.27832 & 0.27335 & 0.16088 \\
\hline & 5 & 0.16285 & 0.11969 & 0.27809 & 0.27678 & 0.16259 \\
\hline
\end{tabular}




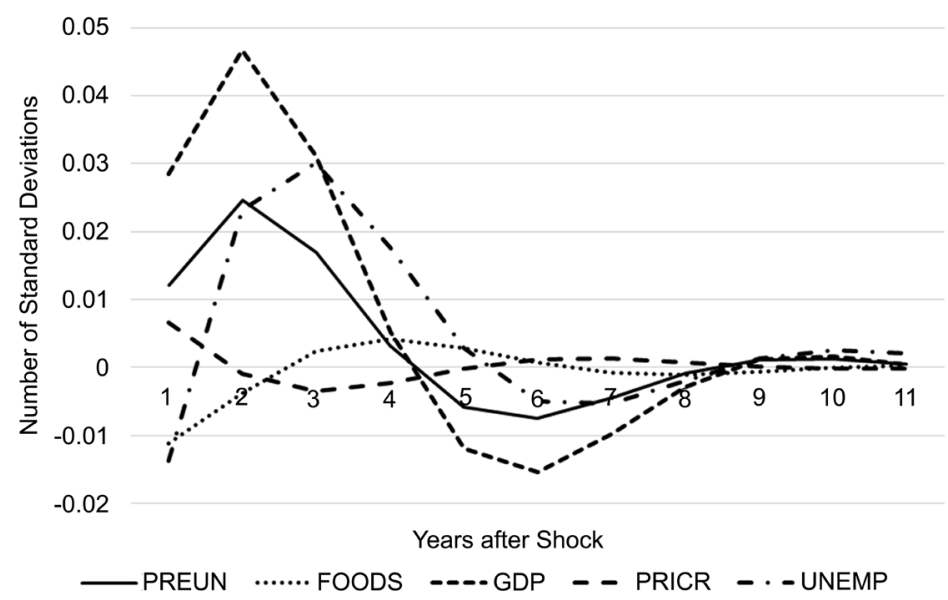

Figure 2. Response of prevalence of undernourishment, food intake, GDP per capita, primary school completion rate, and unemployment rate to a shock in prevalence of undernourishment.

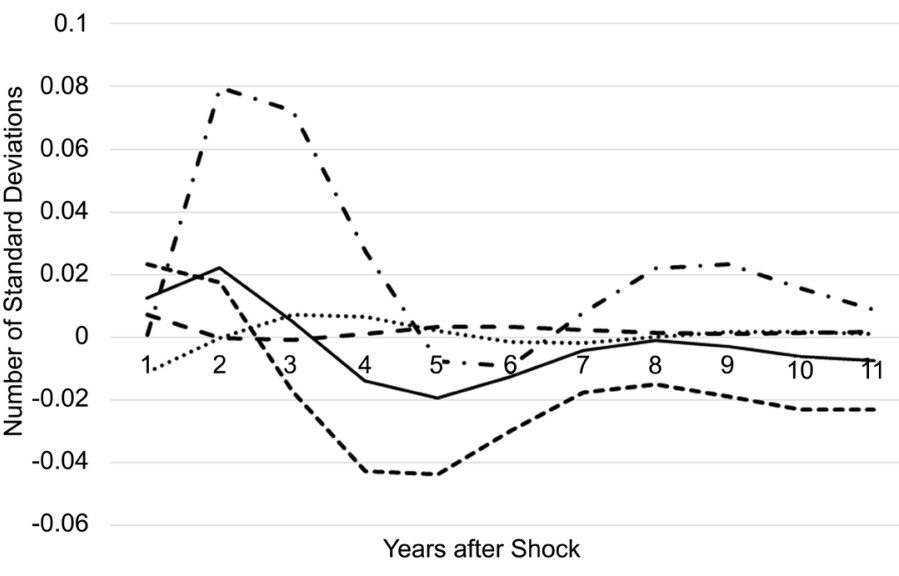

—PREUN ....... FOODS ----.GDP - - PRICR - - -UNEMP

Figure 3. Response of prevalence of undernourishment, food intake, GDP per capita, primary school completion rate, and unemployment rate to a shock in food intake.

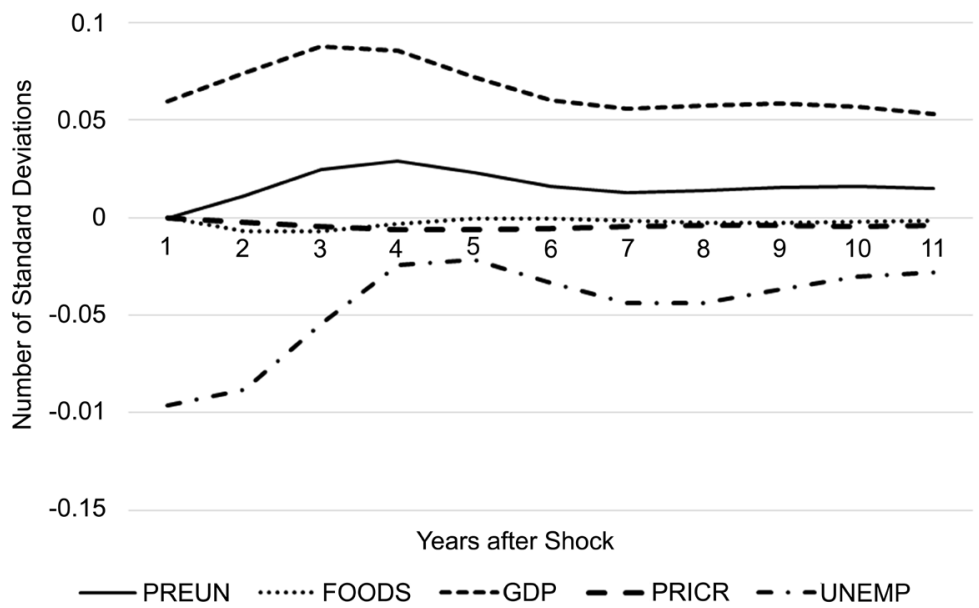

Figure 4. Response of prevalence of undernourishment, food intake, GDP per capita, primary school completion rate, and unemployment rate to a shock in GDP per capita. 


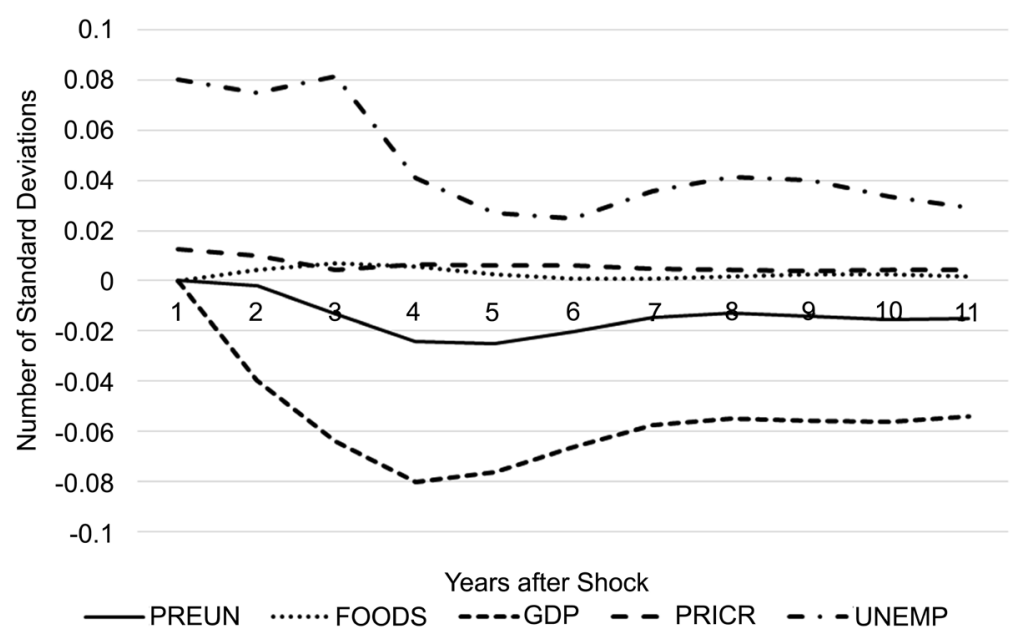

Figure 5. Response of prevalence of undernourishment, food intake, GDP per capita, primary school completion rate, and unemployment rate to a shock in primary school completion rate.

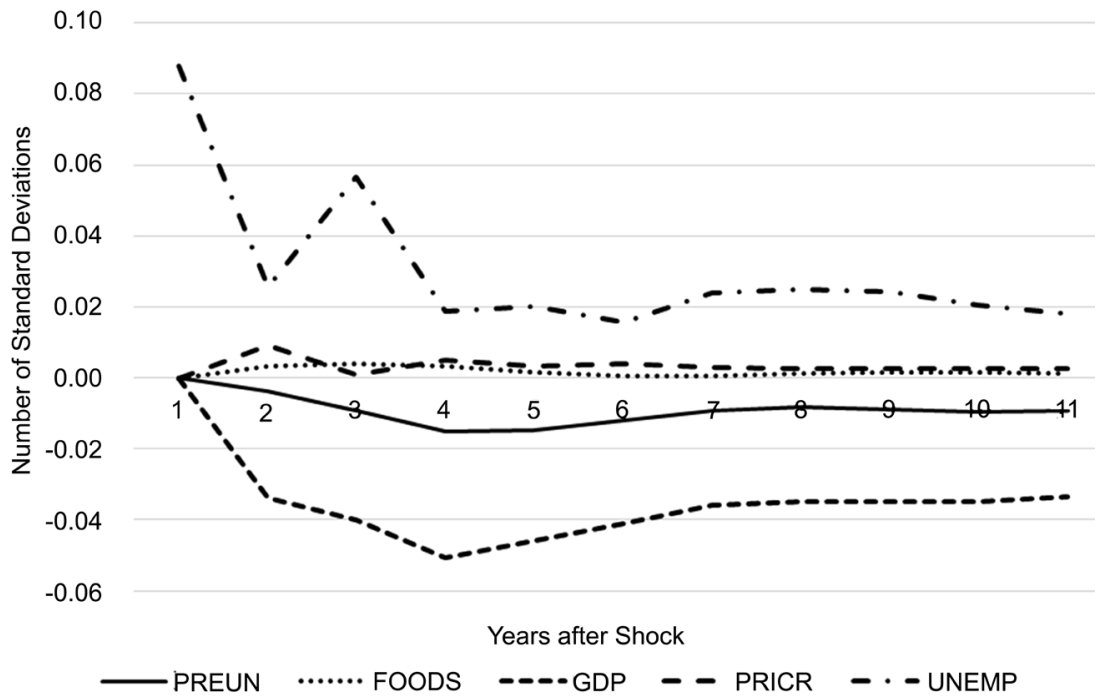

Figure 6. Response of prevalence of undernourishment, food intake, GDP per capita, primary school completion rate, and unemployment rate to a shock in unemployment rate.

responses of food intake and primary school completion rate are small. Figure 3 shows a positive shock in food intake leads to the positive response by unemployment rate and small negative response by GDP per capita. Figure 4 depicts that a positive response in a GDP per capita results in the negative response by unemployment rate. Figure 5 indicates that a positive shock in primary school completion rate leads to a positive response by unemployment rate and a negative response by GDP per capita. Figure 6 shows that a positive shock in unemployment rate results in a negative shock in GDP per capita.

Finally, forecast error variance decompositions are used to interpret the VAR model analysis by many econometric studies [6] [15]. The variance decomposi- 
tion suggests how much information each variable contributes to the other variables in the autoregressive model. Following [15], first, we examined a 10 -year-ahead of forecast error. However, the changes are small after 5 years since we have shorter time series data periods. Therefore, forecast error variance decompositions for a 5-year period are reported (Table 5). Focusing on the prevalence of undernourishment, after five years, twenty-one percent of the variation in the prevalence of undernourishment is explained by its own forecast error. Similarly, ten percent is explained by food intake, thirty-six percent is explained by GDP per capita, twenty-four percent is explained by the primary school completion rate, and nine percent is explained by the unemployment rate. Second twenty-four percent of the variation in food intake is explained by its own forecast error, thirty-five percent is explained by the prevalence of undernourishment, and GDP per capita and the primary school completion rate explain seventeen percent. Only six percent is explained by the unemployment rate. Third, forty-five percent of the variation in GDP per capita is explained by its own forecast error, twenty-eight percent is explained by the primary school completion rate, and eleven percent is explained by the unemployment rate. The prevalence of undernourishment and food intake explain eight percent. Fourth, fifty-three percent of the variation in the primary school completion is explained by its own forecast error, sixteen percent is explained by GDP per capita and eighteen percent is explained by the unemployment rate. The prevalence of undernourishment and food intake explain nine and four percent, respectively. Finally, sixteen percent of the variation in the unemployment rate is explained by its own forecast error, twenty-eight percent is explained by GDP per capita and the primary school completion rate. Sixteen percent is explained by the prevalence of undernourishment, and twelve percent is explained by food intake.

Consistent with economic theory and other studies [12], the forecast error variance decompositions results show that GDP per capita is relatively more influential to other variables. Interestingly, the primary school completion rate has also larger influences to others, indicating that the spillover effects of the primary school completion rate are higher among the Paraguayan development supports. Therefore, supporting early education will have significant indirect impacts on Paraguayan development.

\section{Conclusion}

This research attempts to clarify the spillover effects of international supports in Paraguay. A vector autoregressive model is used to investigate a dynamic linkage among these factors: the prevalence of undernourishment, food intake, GDP per capita, the primary school completion rate, and the unemployment rate. We found that the primary school completion rate was the largest indirect impacts of reducing poverty except GDP per capita, which has commonly largest impacts on its economy. Therefore, supporting organizations such as IDB can maintain the present financial supports/projects and Paraguay can obtain maximum spil- 
lover effects of direct international supports.

\section{Acknowledgements}

This work was supported by Japan Society for the Promotion of Science Grants-in-Aid for Scientific Research (KAKENHI) Grant Number 18K14529.

\section{References}

[1] United Nations Development Programme (2010) What Will It Take to Achieve The Millennium Development Goals? An International Assessment.

http://www.undp.org/content/dam/aplaws/publication/en/publications/MDG/inter national-assessment---english-full-version/IA_English.pdf

[2] Sen, A. and Anand, S. (1997) Concepts of Human Development and Poverty: A Multidimensional Perspective. Poverty and Human Development: Human Development Papers. UNDP, New York, 1-20.

[3] Narayan, D., Patal, R., Schafft, K., Rademacher, A. and Koch-Schulte, S. (2000) Voice of the Poor: Can Anyone Hear Us? World Bank Publication 2000. http://documents.worldbank.org/curated/en/131441468779067441/Voices-of-the-p oor-can-anyone-hear-us

[4] Anand, S. (1983) Inequality and Poverty in Malaysia: Measurement and Decomposition. A World Bank Research Publication, Oxford University Press, Oxford.

[5] Alkire, S. and Santos, M.E. (2010) Acute Multidimensional Poverty: A New Index for Developing Countries. OPHO Working Paper Series 38.

http://ophi.org.uk/acute-multidimensional-poverty-a-new-index-for-developing-co untries/

https://doi.org/10.2139/ssrn.1815243

[6] Siyan, P., Adegoriola, A.E. and Adolphus, J.A. (2015) Unemployment and Inflation: Implication on Poverty Level in Nigeria. Munich Personal RePEc Archive.

https://mpra.ub.uni-muenchen.de/79765/

[7] Dauda, S. and Makinde, O. (2014) Financial Sector Development and Poverty Reduction in Nigeria: A Vector Autoregression Analysis. Asian Economic and Financial Review, 4, 1040-1061.

[8] World Bank (2000) Argentina: Poor People in a Rich Country: Poverty report for Argentina.

http://documents.worldbank.org/curated/en/768561468000279728/Poverty-report-f or-Argentina

[9] World Bank (2001) Brazil-Attacking Brazil's Poverty: A Poverty Report with Focus on Urban Poverty Reduction Policies: Main Report. http://documents.worldbank.org/curated/en/211121468769516128/Main-report

[10] Chiricos, T.G. (1987) Rate of Crime and Unemployment: An Analysis of Aggregate Research Evidence. Social Problems, 34, 187-212. https://doi.org/10.2307/800715

[11] Lopez, J.H. and Perry, G. (2008) Inequality in Latin America: Determinants and Consequences. World Bank Policy Research Working Paper Series. https://openknowledge.worldbank.org/handle/10986/6368

[12] World Bank. (2010) Paraguay-Poverty Assessment: Determinants and Challenges for Poverty Reduction.

http://documents.worldbank.org/curated/en/292191468057267811/Paraguay-Povert $\mathrm{y}$-assessment-determinants-and-challenges-for-poverty-reduction 
[13] Morley, S. and Vos, R.P. (1997) Poverty and Dualistic Growth in Paraguay. ISS Working Papers. https://ideas.repec.org/p/ems/euriss/19004.html

[14] Yamaura, K. and Featherstone, A.M. (2013) Advancing Methodologies for Food Insecurity and Vulnerability Assessment: Potentials for Food Insecurity Risk Insurance through Markets in Sub-Saharan and North Africa Regions. Food and Agriculture Organization at the United Nations (FAO) (mimeo).

[15] Yeager, E. and Featherstone, A.M. (2011) Impact of Changes in Energy Input Prices on Ethanol Importation and Prices. Journal of Agribusiness, 29, 181-200.

[16] Featherstone, A. and Baker, T. (1987) An Examination of Farm Sector Real Asset Dynamics: 1910-85. American Journal of Agricultural Economics, 69, 532-546. https://doi.org/10.2307/1241689 